\title{
Application of Principal Component Analysis on Perceived Barriers to Youth Entrepreneurship
}

\author{
Alice Constance Mensah", Joseph Dadzie \\ Department of Mathematics and Statistics, Accra Technical University, Accra, Ghana \\ Email address: \\ alicecabakah@yahoo.com (A. C. Mensah), kobenagyesi@yahoo.com (J. Dadzie) \\ ${ }^{*}$ Corresponding author
}

To cite this article:

Alice Constance Mensah, Joseph Dadzie. Application of Principal Component Analysis on Perceived Barriers to Youth Entrepreneurship. American Journal of Theoretical and Applied Statistics. Vol. 9, No. 5, 2020, pp. 201-209. doi: 10.11648/j.ajtas.20200905.13

Received: August 20, 2020; Accepted: September 5, 2020; Published: September 21, 2020

\begin{abstract}
Entrepreneurship is an imperative driving force for innovation in a country. Nevertheless, there is lack of systematic investigation in the area of barriers to entrepreneurship and its effects on the intentions of the youth becoming an entrepreneur. As a result, the primary objective of the study is to analyze perceived barriers to youth entrepreneurship. The study used responses from 186 students of a tertiary institution, who were selected based on convenience sampling method. A 5 point likert scale was used to measure the responses and the data analyzed with descriptive statistics, correlation and principal component analysis. The results indicate that youth perceive lack of capital, lack of skill, lack of support, lack of market opportunities and risk as the main barriers to youth entrepreneurship. Nine (9) factors with Eigenvalues greater than one accounted for $73.35 \%$ of the variance explained. The study recommends that, stakeholders precautiously design courses and policies to minimize the perception of entrepreneurship barriers and maximize motivational factors. Entrepreneurship education be designed to enhance skills and knowledge in entrepreneurship and also to reorient students' career choices towards entrepreneurship. Awareness campaign of government support instruments should be done. Policy makers should implement sound economic policies to boost the country's economic environment.
\end{abstract}

Keywords: Youth, Barriers, Entrepreneurship, Principal Component Analysis, Correlation

\section{Introduction}

Entrepreneurship, broadly defined as "any attempt at new venture or new business creation, such as self-employment, a new business organization or the expansion of an existing business, by an individual, a team of individuals, or an established business" [1]. It is an old idea and has always been in practice in the communities and societies. Entrepreneurship brings prosperity and social development since it involves the creation of new ventures that provide goods and services to people, creates jobs, enhances the economic growth and development as well as improving political stability and national security of a country [2 - 4] Involving youth in the formal sector through entrepreneurship is a way of gainfully engaging this population group. According to Mkhize [5] since entrepreneurship is a possible solution to the growing problem of youth joblessness, it is necessary to ensure the success of Small and Micro Enterprises (SMEs).

\subsection{Youth Entrepreneurship}

Creating employment for the growing youth population has been the centre of recent debates in developing countries including Ghana. The household survey data from 2012, puts Ghana's adult population at 34 and 35 percent for age groups 15-24 and 24-35 respectively. These estimates indicate the country's population is young with respect to the adult working age population (defined as ages 15-64).). Uneca \& Ecowas [6] argued that young people are a potential resource for growth and social development if gainfully and productively engaged. It can be accepted that youth entrepreneurship plays a vital role in reducing joblessness levels and contributing to economic growth [7], this will in turn reduce crime, poverty, drug addiction, and income inequality. Ghana can then boast of this if there is ability and capacity to productively engage the youths who form $33.8 \%$ of the population [8]. One form of engagement would be the encouragement and support for youths' to start their own enterprises. 
A young African entrepreneur from Mali, Issah Cheluh, said" The future of Africa's economic development lies with young entrepreneurs". He made this statement while giving a speech at the United Nations first forum on African youth in 2017. Globally, youth unemployment could be attributed to the dearth of "white colour jobs" in the advent of rapid growth and interest in the entrepreneurship and vocational education in Africa today. Hence, the promotion of entrepreneurial and vocational skills acquisition among the youth becomes the best option of reducing youth unemployment. In Issah Cheluh' s speech he confirmed by saying that “ Given Africa's demographic dividend, its related unemployment and the ability of current companies to absorb all the job seekers, entrepreneurship becomes a necessity on the African continent. However, the question is: will African youth deliver or disapprove? I believe entrepreneurship could help Africa and African youth deliver" [9].

The high rate of latent entrepreneurship amongst the young makes youth entrepreneurship attractive to the policy makers. However, there are some barriers that prevent aspiring entrepreneurs, including the youth, from starting a business. There is limited research on the perceived barriers to youth entrepreneurship, in spite of the broad consensus about the importance of entrepreneurship and vocational education to youth empowerment and economic development among nations in Africa [10 - 12]. Against this background, an investigation of the perceived barriers to youth entrepreneurship is very vital and this is what the study seeks to achieve.

\subsection{Barriers to Entrepreneurship}

In general, barriers to entrepreneurship are the "frameable" perceptions in peoples mind concerning starting and managing new businesses. These perceptions become a challenge causing the youth in particular to be confused and distressed. Luthie \& Franke [13] stated that barriers to entrepreneurship relate to "precipitating events", moderating the link between entrepreneurial intention and actual efforts to start an enterprise. These barriers are thus, factors hampering entrepreneurship intents and are also restrictions to one's engagement to be an entrepreneur.

An extensive study of literature by Sitaridis \& Kitsios, [14] categorized barriers to entrepreneurship into internal barriers and external barriers. The internal barriers are fear of risk, lack of confidence, insufficient entrepreneurial skill and negative attitude towards entrepreneurship. To them, external barriers include poor access to capital, lack of institutional support, resource constraints, market related barriers, time consuming registration procedures, bureaucracy, administrative burden and political future uncertainty, etc.

Martins et. al, [15] considered three types of barriers as regulatory barriers, cultural and social barriers and the economic and financial barriers.

A study empirically done by Kebaili et al [16] in Qatar classified barriers as institutional (financial, market and knowledge barriers) and psychological (attitude towards change, risk avoidance, fear of failure and stress avoidance).

In another study, the barriers to the success of entrepreneurship include, high-interest loan from financial institutions, lack of managerial process and zeal and will to take risks [17].

Studies by other authors highlighted lack of capital, less skills and having less ability to develop and train entrepreneurs as important barriers [18 - 21].

Similarly fear of failure, information asymmetry, lack of developed network, administrative complexities and lack of financial support were concluded as barriers to entrepreneurship [22 - 25].

There are multiple barriers to entrepreneurship in different societies but for this study, it include psychological barriers, family related barriers, institutional and regulatory barriers and financial and market barriers. Operationalized family related barriers as lack of family support and motivation. Psychological barriers as fear of failure, attitude towards work, lack of courage and confidence, and risk avoidance. Institutional and regulatory barriers were conceptualized as cost of registration, economic environment and documentation procedures. Financial barriers were classified as lack of financial support and high cost of securing loan. Lack of networking, lack of know how or abilities, lack of information on customer, suppliers and distribution channels were put under market or knowledge barriers.

The outcome of the study will provide practical information on these barriers as well as to propose possible solutions to the problem

\section{Materials and Methodology}

\subsection{Population and Sample}

The study focused on final year students in Accra Technical University. The researcher used the non-probability sampling method (convenience) for the study with a sample size of 200 .

The questionnaire mainly made use of Five-point Likert scale with 1 meaning strongly agree to 5 meaning strongly disagree to determine the obstacles to youth entrepreneurship. It was made up 24 statements on barriers to entrepreneurship as obtained in literature. Close-ended questions were used for demographic variables. The research instrument was developed taken into consideration other similar studies such as [26 - 28]. The data analysis was done using descriptive statistics and principal component analysis.

\subsection{Methodology}

Pishie [29] describe principal component analysis as a multivariate statistical method use to describe variability among observed variables in terms of fewer unobserved variables called factors. Principal component analysis could be used to verify a construct of interest. Principal component analysis has two main purposes. Firstly, it is used for data reduction and secondly for detection of structure (underlying dimensions) in a set of variables. Leech et al [30], point out that the decision about which factor to retain depends on the percentage of the variance accounted for the variable, the absolute variance accounted for by each factor, and whether 
the factor can be meaningfully interpreted. Factors with Eigenvalues greater than one are usually retained.

Sample adequacy should be assessed, and two tests can be applied: the Kaiser-Meyer-Olkin (KMO) test and Bartlett's sphericity test. KMO statistic is a proportion of variance among variables that might be common variance: varies from zero to one, in which zero is inadequate, while close to one is adequate.

Bartlett's test compares the observed correlation matrix to the identity matrix (off-diagonal is zero). If they are similar, it will be necessary as many factors as variables, and the analysis is useless. Overall, KMO values above 0.50 and $\mathrm{p}<$ 0.05 for Bartlett's sphericity test are considered acceptable.

\subsection{Principal Component Analysis}

Assume the random variables $X_{1} \ldots, X_{p}$ of interest have a certain multivariate distribution with mean vector $\mu$ and covariance matrix $\sum$ which are finite. The rank of $\sum$ is $r \leq p$, and the $\mathrm{q}$ largest characteristic roots

$$
\lambda_{1}>\cdots \lambda_{q}
$$

of $\sum$ are all district. From this population a sample of $\mathrm{N}$ independent observation vectors has been drawn. The observations can be written as usual $\mathrm{N} x \mathrm{p}$ data matrix

$$
\mathrm{X}=\left[\begin{array}{ccc}
x_{11} & \cdots & x_{1 p} \\
\vdots & \ddots & \vdots \\
x_{N 1} & \cdots & x_{N p}
\end{array}\right]
$$

For the measure of dependence, each $\mathrm{x}_{\mathrm{ij}}$ is transformed to a standard score

$$
Z_{i j}=\frac{x_{i j}-\bar{x}_{j}}{s_{j}}
$$

\subsection{Sample Covariance Matrix}

The first principal component of the observation $\mathrm{X}$ by the linear transformation

$$
z_{1} \equiv a_{1}^{T} X=\sum_{i=1}^{p} a_{i 1} x_{i}
$$

Where the $a_{1}=\left(a_{11}, a_{21} \ldots a_{p 1}\right)$ is chosen such that var $\left[z_{1}\right]$ is maximum

Thus, $\mathrm{k}^{\text {th }} \mathrm{PC}$ of the sample by the linear transformation

$$
z_{k} \equiv a_{k}^{T} X
$$

$\mathrm{k}=1 \ldots \mathrm{p}$

Where the $a_{k}=\left(a_{1 k}, a_{2 k}, \ldots, a_{p k}\right)$

Is chosen such that var $\left[z_{k}\right]$ is maximum

Subject to $\operatorname{cov}\left[\mathrm{z}_{\mathrm{k}}, \mathrm{z}_{1}\right]=0$ for $\mathrm{k}>1 \geq 1$

And to $a_{k}^{T} a_{k}=1$

To find $\mathrm{a}_{1}$ note that

$$
\begin{gathered}
\operatorname{var}\left[z_{1}\right]=\left\langle z_{1}^{2}\right\rangle-\left\langle z_{1}\right\rangle 2 \\
=\sum_{i, j=1}^{p} a_{i 1} a_{j 1}\left\langle x_{i} x_{j}\right\rangle-\sum_{i, j=1}^{p} a_{i 1} a_{j 1}\left\langle x_{i}\right\rangle\left\langle x_{j}\right\rangle \\
=\sum_{i, j,=1}^{p} a_{i 1} a_{j 1} S_{i j}
\end{gathered}
$$

$$
\begin{gathered}
\text { Where } \mathrm{S}_{\mathrm{ij}} \equiv \sigma_{x i x j}=\left\langle x_{i} x_{j}\right\rangle-\left\langle x_{i}\right\rangle\left\langle x_{j}\right\rangle \\
=a_{1}^{T} S_{a 1}
\end{gathered}
$$

$\mathrm{S}$ is the covariance matrix for the variables $\mathrm{x}=\left(\mathrm{x}_{1}, \mathrm{x}_{2}, \ldots\right.$ $\mathrm{x}_{\mathrm{p}}$ )

To find $a_{1}$ maximize var $\left[z_{1}\right]$ subject to $a_{1}^{T} a_{1}=1$

Let $\lambda$ be a Lagrange multiplier

Then maximize $a_{1}^{T} S_{a 1}-\lambda\left(a_{1}^{T} a_{1}-1\right)$

By differentiating $S a_{1}-\lambda a_{1}=0$

$$
\Rightarrow\left(S-\lambda I_{p}\right) a_{1}=0
$$

Therefore $\mathrm{a}_{1}$ is an eigenvector of $\mathrm{S}$ corresponding to eigenvalue $\lambda \equiv \lambda_{1}$

Maximized $\operatorname{var}\left[\mathrm{z}_{1}\right]=a_{1}^{T} S_{a 1}=a_{1}^{T} \lambda_{1} a_{1}=\lambda_{1}$

So $\lambda_{1}$ is the largest eigenvalue of $\mathrm{S}$.

The first $\mathrm{PC} \mathrm{z}_{1}$ retains the greatest amount of variation in the sample.

In general

$$
\begin{aligned}
Y_{i j} & =\beta_{i 1} X_{1 j}+\beta_{i 2} X_{2 j}+\cdots+\beta_{i p} X_{p j} \\
& =a_{1}^{\prime} x
\end{aligned}
$$

of the responses whose sample variance

$$
\begin{aligned}
S_{Y 1}^{2} & =\sum_{i=1}^{p} \sum_{j=i}^{p} a_{i 1} a_{j 1} s_{i j} \\
& =a_{1}^{\prime} S
\end{aligned}
$$

Where $i, j=1,2, \ldots, p$

A transformation of the factor loadings and the resulted transformation of the factors are called factor rotation. It happens in so many cases that all factor loadings obtained from initial loadings by an orthogonal transformation are not easily interpretable. It is therefore a common practice to rotate them in some way to achieve a simpler structure. In fact, it is always desirable to have a pattern of loadings such that each variable is loaded high on a single factor and has small loadings on the remaining factors. This transformation rotates the common factors in $\mathrm{m}$-dimensional space. Moreover, there are various methods of carrying out factor analysis, however in this study factor rotation using VARIMAX method is used.

\subsection{Factor Rotation Using VARIMAX Method}

The most common method for factor rotation is the VAIMAX procedure, which maintains axes at right angles. This is the method that also minimizes the number of variables with high loadings on a factor.

Let the rotated matrix of factor loadings be denoted by $\mathrm{L}^{*}=$ $\left[\mathrm{I}_{\mathrm{ij}}{ }^{*}\right]$ and $\mathrm{c}_{\mathrm{i}}{ }^{2}$ represent the $\mathrm{i}^{\text {th }}$ communality then, $\widetilde{l_{l \jmath}}=l_{i j}^{*} / c_{i}$ is defined as the rotated coefficient in terms of square root communalities. If $\mathrm{P}$ is an ' $\mathrm{m} \mathrm{x} \mathrm{m}$ ' orthogonal matrix such that $\mathrm{L}^{*}=\mathrm{LP}$ and $\mathrm{F}^{*}=\mathrm{P}^{\prime} \mathrm{F}$, then the matrix $\mathrm{P}$ is chosen to maximize the following:

$$
V=\frac{1}{k} \sum_{j=1}^{m}\left[\sum_{i=1}^{k}\left(l_{i j}^{*}\right)^{4}-\frac{1}{k}\left(\sum_{i=1}^{k} \tilde{l}_{i j}^{* 2}\right)^{2}\right]
$$


Where maximized value of ' $\mathrm{V}$ ' means that squares of the loadings are spread out on each variable as much as possible. The interpretations of common factors become simpler by finding groups of very large and very small coefficients in any column of the rotated matrix of factor loadings.

\section{Results and Discussions}

\subsection{Data Analysis}

Table 1 summarizes the demographic profile of the respondents. The questionnaires were distributed to 200 students but 186 were valid for analysis. Male respondents were $114(61.3 \%)$ and $72(38.7 \%)$ were females. Majority of the students $72.6 \%$ were aged between $20-24$ years followed by those in age bracket $25-29$, representing $22.6 \%$ of the respondents. Again, majority of respondents $(51.10 \%)$ were from the faculty of business.

Table 1. Demographic profile of respondents.

\begin{tabular}{lll}
\hline Variable/Level & Frequency $(\mathbf{N}=\mathbf{1 8 6})$ & Percent $(\%)$ \\
\hline Gender & & \\
Male & 114 & 61.3 \\
Female & 72 & 38.7 \\
Age group & & \\
20-24 years & 135 & 72.6 \\
$25-29$ years & 42 & 22.6 \\
$30-34$ years & 6 & 3.2 \\
$>34$ years & 3 & 1.6 \\
Faculty & & \\
FAS & 51 & 27.4 \\
\hline
\end{tabular}

\begin{tabular}{lll}
\hline Variable/Level & Frequency $(\mathbf{N}=\mathbf{1 8 6})$ & Percent $(\%)$ \\
\hline FOB & 95 & 51.1 \\
FOE & 40 & 21.5 \\
\hline
\end{tabular}

\subsection{Item Descriptive and Normality Testing}

The responses to the entrepreneur's barriers ranged from strongly agree (1) to disagree (5). To make the interpretation very simple, the following coding system was used. Mean value between (1.00-2.99) indicates agreement, (4.00-5.00) indicates disagreement while between (3.00-3.99) indicates undecided. Table 2 presents the descriptive statistics and the reliability analysis of the items. Descriptive statistics such as the mean, standard deviation, skewness and kurtosis were used to describe the data. The mean $(\bar{x})$ value for the items ranged from 2.081 to 3.29. Based on the result, there is an indication that respondents (students) were in agreement with 23 of the statements out of 26. This shows that almost all the barriers listed were perceived to be important in inhibiting the youth's decision to be self-employed or an entrepreneur. For instance, the estimated mean value for lack of information is 2.194, this is an indication student agreed to the perception that there is lack of information about youth entrepreneurship. It can be said that, the average score for all the items have a similar spread, with difficult bank finance being the most significant factor followed by lack of information.

The internal consistency of measurement items was assessed using Cronbach's alpha. The overall cronbach's alpha for all the items was $(\alpha=0.811)$ which is above the recommended value of 0.70 .

Table 2. Descriptive Statistics.

\begin{tabular}{|c|c|c|c|c|c|c|}
\hline Item & $\bar{X}$ & SD & Skewness & kurtosis & $\alpha$ & $\alpha$ if Item Deleted \\
\hline Lack of information & 2.194 & 1.239 & 0.954 & -0.178 & 0.811 & 0.805 \\
\hline Lack of skills & 3.097 & 1.224 & -0.079 & -1.267 & & 0.808 \\
\hline Difficult bank finance & 2.081 & 1.232 & 0.983 & 0.005 & & 0.800 \\
\hline Can't write business plan & 2.629 & 1.149 & 0.310 & -0.882 & & 0.804 \\
\hline No family member did it & 3.113 & 1.415 & -0.242 & -1.315 & & 0.812 \\
\hline Fear of crime & 2.613 & 1.347 & 0.334 & -1.058 & & 0.821 \\
\hline No opportunity in the market & 2.903 & 1.339 & -0.114 & -1.323 & & 0.813 \\
\hline Future uncertainty & 2.855 & 1.278 & 0.232 & -1.061 & & 0.807 \\
\hline Repaying school loans & 2.839 & 1.308 & 0.309 & -1.103 & & 0.808 \\
\hline Right partner difficulty & 2.565 & 1.250 & 0.526 & -0.706 & & 0.801 \\
\hline Weak economic environment & 2.226 & 1.247 & 0.918 & -0.116 & & 0.793 \\
\hline Lack of funding information & 2.242 & 1.289 & 1.048 & 0.075 & & 0.794 \\
\hline Lack of savings & 2.339 & 1.318 & 0.852 & -0.395 & & 0.806 \\
\hline Lack of family and friends support & 2.790 & 1.381 & 0.314 & -1.197 & & 0.800 \\
\hline Lack of collateral & 2.500 & 1.251 & 0.467 & -0.763 & & 0.802 \\
\hline No one helping & 2.468 & 1.339 & 0.769 & -0.657 & & 0.797 \\
\hline Lack of business experience & 2.468 & 1.238 & 0.586 & -0.634 & & 0.804 \\
\hline Fear of risk & 2.355 & 1.438 & 0.814 & -0.758 & & 0.801 \\
\hline No people encouraging & 2.548 & 1.327 & 0.502 & -1.034 & & 0.796 \\
\hline No management and entrepreneurial knowledge & 2.806 & 1.353 & 0.200 & -1.256 & & 0.802 \\
\hline High registration costs & 2.371 & 1.258 & 0.737 & -0.348 & & 0.813 \\
\hline Don't have a good idea & 2.935 & 1.366 & 0.080 & -1.248 & & 0.805 \\
\hline Don't have the right contacts & 2.452 & 1.289 & 0.656 & -0.680 & & 0.805 \\
\hline Not the right time for me, want to do other things first & 2.887 & 1.332 & 0.127 & -1.287 & & 0.807 \\
\hline I am too young & 3.290 & 1.395 & -0.355 & -1.218 & & 0.809 \\
\hline Involves too much work and effort & 2.935 & 1.436 & 0.117 & -1.382 & & 0.806 \\
\hline maximum & 3.29 & 1.438 & 1.048 & 0.075 & & 0.821 \\
\hline Min & 2.081 & 1.149 & -0.355 & -1.382 & & 0.793 \\
\hline
\end{tabular}

The pair wise correlations were computed to measure the relationship as shown in table 3. All principal component 
techniques try to batch subcategories of variables together based on their correlations. Most often than not, by examining the correlation matrix, it helps to spot clusters of high correlations between groups of variables. From the correlation matrix, table 3 , there exists positive degree of relationship between majorities of the barrier factors being considered.

Table 3. Correlation Matrix.

\begin{tabular}{|c|c|c|c|c|c|c|c|c|c|c|c|c|}
\hline & LoI & LoS & DBF & BP & Nfam & FoC & NoM & FU & RSL & RPD & WEE & LoFI \\
\hline LoI & 1.000 & & & & & & & & & & & \\
\hline LoS & 0.225 & 1.000 & & & & & & & & & & \\
\hline $\mathrm{DBF}$ & 0.151 & 0.245 & 1.000 & & & & & & & & & \\
\hline BP & 0.362 & 0.399 & 0.357 & 1.000 & & & & & & & & \\
\hline Nfam & 0.118 & 0.013 & 0.117 & -0.115 & 1.000 & & & & & & & \\
\hline FoC & -0.033 & -0.136 & -0.119 & 0.043 & 0.290 & 1.000 & & & & & & \\
\hline NoM & 0.002 & -0.084 & 0.213 & 0.008 & 0.144 & 0.061 & 1.000 & & & & & \\
\hline $\mathrm{FU}$ & 0.070 & 0.030 & 0.237 & -0.004 & 0.381 & 0.024 & 0.221 & 1.000 & & & & \\
\hline RSL & 0.141 & 0.041 & 0.100 & 0.080 & 0.107 & 0.104 & 0.019 & 0.084 & 1.000 & & & \\
\hline RPD & 0.129 & 0.189 & 0.098 & 0.343 & 0.149 & 0.259 & -0.104 & 0.196 & 0.257 & 1.000 & & \\
\hline WEE & 0.279 & 0.286 & 0.351 & 0.288 & 0.013 & 0.043 & 0.043 & 0.227 & 0.163 & 0.506 & 1.000 & \\
\hline LoFI & 0.288 & 0.026 & 0.390 & 0.051 & 0.299 & -0.040 & 0.042 & 0.410 & 0.276 & 0.290 & 0.516 & 1.000 \\
\hline Lsav & 0.130 & -0.061 & 0.205 & -0.132 & 0.155 & -0.119 & 0.065 & 0.166 & 0.023 & -0.028 & 0.202 & 0.395 \\
\hline LoFS & 0.235 & 0.099 & 0.164 & 0.064 & 0.138 & -0.203 & 0.361 & 0.196 & 0.172 & 0.089 & 0.257 & 0.315 \\
\hline LoC & 0.074 & -0.032 & 0.356 & 0.154 & 0.023 & 0.029 & 0.147 & 0.169 & 0.320 & 0.351 & 0.357 & 0.381 \\
\hline $\mathrm{NoH}$ & 0.073 & 0.052 & 0.315 & 0.125 & 0.136 & -0.107 & 0.345 & -0.008 & 0.362 & 0.075 & 0.250 & 0.418 \\
\hline LBEx & 0.058 & 0.078 & 0.168 & 0.113 & -0.003 & -0.076 & 0.107 & 0.189 & -0.003 & 0.102 & 0.228 & 0.267 \\
\hline FoR & 0.218 & 0.120 & 0.122 & 0.012 & -0.052 & -0.224 & 0.061 & 0.153 & 0.066 & 0.078 & 0.320 & 0.466 \\
\hline NE & 0.263 & 0.098 & 0.163 & 0.286 & -0.130 & -0.017 & 0.141 & 0.028 & 0.231 & 0.315 & 0.410 & 0.228 \\
\hline NMEK & 0.218 & 0.348 & 0.275 & 0.301 & -0.023 & -0.105 & 0.053 & -0.092 & 0.038 & 0.124 & 0.240 & 0.131 \\
\hline HRC & -0.026 & 0.061 & -0.020 & -0.085 & 0.059 & 0.047 & -0.144 & -0.068 & 0.087 & 0.136 & 0.197 & 0.166 \\
\hline GI & 0.269 & 0.337 & 0.198 & 0.350 & -0.200 & -0.147 & -0.048 & -0.081 & -0.033 & 0.175 & 0.365 & 0.046 \\
\hline $\mathrm{RC}$ & 0.334 & 0.169 & 0.235 & 0.204 & -0.082 & -0.134 & -0.098 & -0.009 & 0.063 & 0.063 & 0.323 & 0.229 \\
\hline NRT & 0.023 & -0.084 & 0.056 & 0.015 & 0.346 & 0.304 & 0.049 & 0.318 & 0.055 & 0.088 & 0.025 & 0.312 \\
\hline TY & -0.099 & 0.050 & 0.196 & 0.222 & 0.041 & -0.087 & 0.059 & 0.134 & 0.053 & 0.196 & 0.178 & -0.021 \\
\hline TMWE & 0.026 & 0.181 & 0.123 & 0.254 & 0.109 & 0.004 & -0.020 & -0.014 & 0.021 & 0.395 & 0.201 & 0.168 \\
\hline
\end{tabular}

Table 3. Continued.

\begin{tabular}{|c|c|c|c|c|c|c|c|c|c|c|c|c|c|c|}
\hline & Lsav & LoFS & LoC & NoH & LBEx & FoR & NE & NMEK & HRC & GI & RC & NRT & TY & TMWE \\
\hline \multicolumn{15}{|l|}{ LoI } \\
\hline \multicolumn{15}{|l|}{ LoS } \\
\hline \multicolumn{15}{|l|}{ DBF } \\
\hline \multicolumn{15}{|l|}{$\mathrm{BP}$} \\
\hline \multicolumn{15}{|l|}{ Nfam } \\
\hline \multicolumn{15}{|l|}{ FoC } \\
\hline \multicolumn{15}{|l|}{ NoM } \\
\hline \multicolumn{15}{|l|}{ FU } \\
\hline \multicolumn{15}{|l|}{ RSL } \\
\hline \multicolumn{15}{|l|}{ RPD } \\
\hline \multicolumn{15}{|l|}{ WEE } \\
\hline \multicolumn{15}{|l|}{ LoFI } \\
\hline Lsav & 1.000 & & & & & & & & & & & & & \\
\hline LoFS & 0.400 & 1.000 & & & & & & & & & & & & \\
\hline LoC & 0.254 & 0.299 & 1.000 & & & & & & & & & & & \\
\hline $\mathrm{NoH}$ & 0.429 & 0.541 & 0.386 & 1.000 & & & & & & & & & & \\
\hline LBEx & 0.243 & 0.001 & 0.058 & 0.242 & 1.000 & & & & & & & & & \\
\hline FoR & 0.282 & 0.112 & 0.064 & 0.236 & 0.495 & 1.000 & & & & & & & & \\
\hline $\mathrm{NE}$ & 0.323 & 0.305 & 0.257 & 0.351 & 0.450 & 0.420 & 1.000 & & & & & & & \\
\hline NMEK & 0.065 & 0.206 & 0.000 & 0.233 & 0.319 & 0.230 & 0.480 & 1.000 & & & & & & \\
\hline HRC & 0.190 & -0.039 & -0.109 & 0.032 & 0.076 & 0.216 & 0.348 & 0.245 & 1.000 & & & & & \\
\hline GI & 0.021 & 0.114 & 0.038 & 0.142 & 0.280 & 0.279 & 0.282 & 0.250 & 0.054 & 1.000 & & & & \\
\hline $\mathrm{RC}$ & 0.179 & 0.367 & 0.457 & 0.246 & 0.102 & 0.089 & 0.217 & 0.314 & -0.044 & 0.371 & 1.000 & & & \\
\hline NRT & 0.125 & 0.058 & 0.084 & 0.168 & 0.132 & 0.124 & -0.094 & 0.124 & 0.074 & 0.041 & 0.107 & 1.000 & & \\
\hline TY & -0.090 & 0.083 & 0.047 & 0.110 & -0.031 & 0.144 & 0.072 & 0.091 & -0.025 & 0.303 & -0.047 & 0.327 & 1.000 & \\
\hline TMWE & -0.092 & 0.134 & 0.064 & 0.144 & 0.017 & 0.249 & 0.088 & 0.112 & 0.068 & 0.240 & -0.011 & 0.236 & 0.566 & 1.000 \\
\hline
\end{tabular}

\subsection{Exploratory Factor Analysis}

The Kaiser-Meyer-Olkin measure and Bartlett's test were employed to be sure of the usage of factor analysis (principal component) for the study.

Null Hypothesis: The inter-correlation matrix of the variables is not different from an identity matrix. 
Alternative Hypothesis: The inter-correlation matrix of the variables is different from an identity matrix.

Table 4. Kaiser-Meyer-Olkin Measure of Sampling Adequacy Bartlett's Test of Sphericity.

\begin{tabular}{lll}
\hline \multicolumn{3}{c}{ KMO and Bartlett's Test } \\
\hline Kaiser-Meyer-Olkin Measure of Sampling Adequacy. & 0.611 \\
Bartlett's Test of Sphericity & Approx. Chi-Square & 577.373 \\
& df & 325 \\
& Sig. & 0.000 \\
\hline
\end{tabular}

The KMO value of 0.611 that the inter-relationships of the variables are of good precision. The Bartlett's test of sphericity $(577.373, \mathrm{df}=325)$ with an associated p-value of 0.000 indicating that, the correlation matrix is significantly different from an identity matrix. Since the value of KMO exceeds 0.5 , using factor separation based on fundamental concepts is allowable.

Varimax rotation is used in the implemented factor analysis to separate the items based on factor load coefficient determining the factor to which each item belongs. The questionnaire was submitted for examination using confirmed factor analysis technique during which items with factor load less than $0.5(<0.5)$ were omitted out of the 26 items. Finally 24 items were retained for further analysis.

In order to identify similar movement pattern in each PC, the Eigen values and the associated percentage of variance are considered. The results of the component analysis is shown in table 5, of which nine main components with Eigen values greater than 1 explained $73.35 \%$ of the variance. The first component explains about $20.14 \%$ of the total variance. The second component explains about $10.4 \%$ of the overall variance, etc. It is found that the first component recorded the greatest variance followed by the second component with the remaining components following the same decreasing trend of variance.

Table 5. Total Variance Explained.

\begin{tabular}{|c|c|c|c|c|c|c|c|c|c|}
\hline \multirow[b]{2}{*}{ Component } & \multirow[b]{2}{*}{ Total } & \multicolumn{2}{|c|}{ Initial Eigenvalues } & \multicolumn{3}{|c|}{ Extraction Sums of Squared Loadings } & \multicolumn{3}{|c|}{ Rotation Sums of Squared Loadings } \\
\hline & & $\%$ of Variance & Cumulative \% & Total & $\%$ of Variance & Cumulative \% & Total & $\%$ of Variance & Cumulative \% \\
\hline 1 & 4.835 & 20.146 & 20.146 & 4.835 & 20.146 & 20.146 & 2.44 & 10.169 & 10.169 \\
\hline 2 & 2.496 & 10.399 & 30.545 & 2.496 & 10.399 & 30.545 & 2.26 & 9.423 & 19.592 \\
\hline 3 & 2.174 & 9.057 & 39.602 & 2.174 & 9.057 & 39.602 & 2.16 & 9.009 & 28.602 \\
\hline 4 & 1.74 & 7.251 & 46.853 & 1.74 & 7.251 & 46.853 & 2.12 & 8.816 & 37.418 \\
\hline 5 & 1.572 & 6.55 & 53.403 & 1.572 & 6.55 & 53.403 & 2.11 & 8.799 & 46.217 \\
\hline 6 & 1.296 & 5.401 & 58.804 & 1.296 & 5.401 & 58.804 & 1.99 & 8.305 & 54.522 \\
\hline 7 & 1.254 & 5.227 & 64.031 & 1.254 & 5.227 & 64.031 & 1.56 & 6.501 & 61.023 \\
\hline 8 & 1.164 & 4.851 & 68.882 & 1.164 & 4.851 & 68.882 & 1.51 & 6.273 & 67.297 \\
\hline 9 & 1.072 & 4.465 & 73.347 & 1.072 & 4.465 & 73.347 & 1.45 & 6.05 & 73.347 \\
\hline 10 & 0.826 & 3.44 & 76.787 & & & & & & \\
\hline 11 & 0.746 & 3.11 & 79.897 & & & & & & \\
\hline 12 & 0.687 & 2.864 & 82.761 & & & & & & \\
\hline 13 & 0.644 & 2.683 & 85.444 & & & & & & \\
\hline 14 & 0.565 & 2.356 & 87.799 & & & & & & \\
\hline 15 & 0.462 & 1.926 & 89.726 & & & & & & \\
\hline 16 & 0.455 & 1.898 & 91.623 & & & & & & \\
\hline 17 & 0.414 & 1.723 & 93.347 & & & & & & \\
\hline 18 & 0.325 & 1.353 & 94.7 & & & & & & \\
\hline 19 & 0.316 & 1.318 & 96.018 & & & & & & \\
\hline 20 & 0.257 & 1.072 & 97.09 & & & & & & \\
\hline 21 & 0.22 & 0.917 & 98.007 & & & & & & \\
\hline 22 & 0.191 & 0.796 & 98.803 & & & & & & \\
\hline 23 & 0.151 & 0.629 & 99.432 & & & & & & \\
\hline 24 & 0.136 & 0.568 & 100 & & & & & & \\
\hline
\end{tabular}

Extraction Method: Principal Component Analysis.

Table 6. Rotated component matrix and communalities.

\begin{tabular}{|c|c|c|c|c|c|c|c|c|c|c|}
\hline & 1 & 2 & 3 & 4 & 5 & 6 & 7 & 8 & 9 & communalities \\
\hline Lack of information & 0.44 & -0.155 & -0.084 & -0.206 & 0.323 & 0.461 & 0.031 & 0.041 & -0.058 & 0.589 \\
\hline Lack of skills & 0.335 & -0.472 & 0.104 & -0.097 & 0.088 & 0.376 & 0.089 & 0.041 & -0.341 & 0.63 \\
\hline Can't write business plan & 0.417 & -0.489 & 0.26 & -0.302 & 0.08 & 0.086 & 0.233 & -0.157 & 0.051 & 0.667 \\
\hline No family member did it & 0.133 & 0.572 & 0.382 & 0.026 & 0.146 & 0.327 & 0.198 & 0.2 & -0.179 & 0.731 \\
\hline Fear of crime & -0.095 & 0.225 & 0.479 & 0.011 & 0.436 & -0.191 & 0.433 & 0.027 & 0.303 & 0.795 \\
\hline No opportunity in the market & 0.178 & 0.366 & -0.1 & -0.199 & -0.385 & 0.012 & 0.543 & -0.355 & -0.077 & 0.791 \\
\hline Future uncertainty & 0.287 & 0.505 & 0.268 & 0.023 & 0.058 & 0.348 & -0.146 & -0.397 & -0.1 & 0.723 \\
\hline Right partner difficulty & 0.473 & -0.095 & 0.517 & -0.056 & 0.339 & -0.355 & -0.026 & -0.157 & -0.164 & 0.796 \\
\hline Weak economic environment & 0.707 & -0.092 & 0.124 & -0.032 & 0.257 & -0.154 & -0.159 & -0.161 & -0.147 & 0.687 \\
\hline Lack of funding information & 0.653 & 0.425 & 0.027 & 0.111 & 0.193 & 0.083 & -0.3 & -0.001 & -0.076 & 0.761 \\
\hline Lack of savings & 0.438 & 0.431 & -0.405 & 0.14 & 0.018 & -0.056 & -0.11 & 0.197 & -0.054 & 0.618 \\
\hline Lack of family and friends support & 0.539 & 0.274 & -0.254 & -0.393 & -0.254 & 0.015 & 0.115 & 0.189 & -0.275 & 0.774 \\
\hline Lack of collateral & 0.479 & 0.251 & -0.04 & -0.459 & 0.14 & -0.412 & -0.199 & -0.099 & 0.186 & 0.779 \\
\hline
\end{tabular}




\begin{tabular}{|c|c|c|c|c|c|c|c|c|c|c|}
\hline & 1 & 2 & 3 & 4 & 5 & 6 & 7 & 8 & 9 & communalities \\
\hline No one helping & 0.587 & 0.287 & -0.24 & -0.163 & -0.31 & -0.193 & 0.19 & 0.164 & 0.009 & 0.707 \\
\hline Lack of business experience & 0.472 & -0.012 & -0.183 & 0.465 & -0.052 & 0.116 & 0.097 & -0.39 & 0.362 & 0.781 \\
\hline Fear of risk & 0.558 & -0.014 & -0.143 & 0.514 & -0.179 & 0.111 & -0.239 & -0.185 & 0.008 & 0.732 \\
\hline No people encouraging & 0.663 & -0.169 & -0.254 & 0.235 & 0.084 & -0.3 & 0.3 & -0.127 & -0.006 & 0.791 \\
\hline $\begin{array}{l}\text { No management and entrepreneurial } \\
\text { knowledge }\end{array}$ & 0.504 & -0.335 & -0.125 & 0.166 & -0.012 & 0.15 & 0.416 & 0.252 & 0.09 & 0.677 \\
\hline High registration costs & 0.214 & -0.053 & -0.028 & 0.603 & 0.236 & -0.24 & 0.11 & 0.405 & -0.245 & 0.763 \\
\hline Don't have a good idea & 0.481 & -0.524 & 0.034 & -0.018 & -0.167 & 0.122 & -0.123 & -0.008 & 0.222 & 0.615 \\
\hline Don't have the right contacts & 0.495 & -0.141 & -0.258 & -0.421 & 0.161 & 0.088 & -0.211 & 0.296 & 0.369 & 0.811 \\
\hline Not the right time for me & 0.256 & 0.385 & 0.471 & 0.145 & -0.13 & 0.226 & 0.017 & 0.32 & 0.477 & 0.855 \\
\hline I am too young & 0.259 & -0.141 & 0.547 & 0.016 & -0.608 & -0.103 & -0.12 & 0.056 & 0.028 & 0.785 \\
\hline Involves too much work and effort & 0.355 & -0.179 & 0.579 & 0.053 & -0.392 & -0.153 & -0.123 & 0.163 & -0.171 & 0.744 \\
\hline
\end{tabular}

\section{Scree Plot}

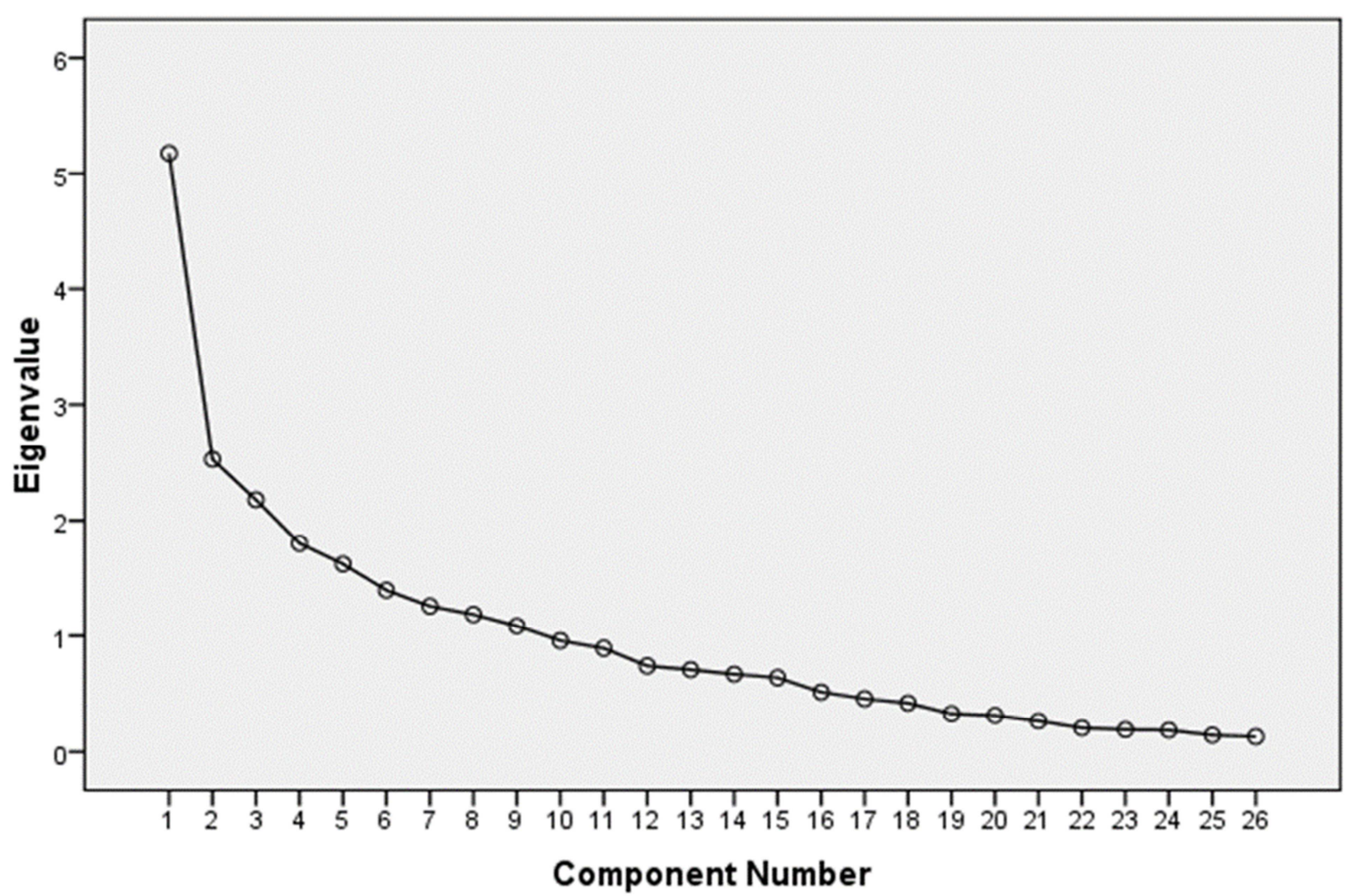

Figure 1. Screen Plot of Ordered Eigen Value.

Table 6 reveals component 1 is highly correlated with 11 original variables of perceived barriers to youth entrepreneurship, lack of financial support, family support and motivation. Other studies also assert that lack of financial support hinders youth entrepreneurship, [23, 25]. Component 2 is also correlated with 5 original variables, lack of skills and ideas, which is consistent with studies done by [19, 23]. Whiles component 3 is also strongly correlated with 3 original variables, psychological barriers, this finding is in line with [23]. The remaining 6 components correlated with a variable each. Historically, literature shows that mostly PC1 or only few PCs contain maximum information [31 - 33]. Therefore, the first 7 PCs are significant among the nine constructed PCs as they contain $64.04 \%$ variation and the remaining 2 have less than 5\% variation. Cattell's scree test requires visual analysis of a graphical representation of eigenvalues for point of inflection and this shown in figure 1 .

\section{Conclusions and Recommendation}

The study empirically investigated perceived barriers to youth entrepreneurship in Ghana. The first seven (7) perceived barriers were found to be significant among the nine constructed PCs and positively correlated with student's perception to youth entrepreneurship. These are lack of supporting systems - lack of financial, technical and family 
support and weak economic environment. Another perceived barriers are lack of skills and ideas, uncertainty and lack of market opportunities among others. Thus, results of this study indicate that there are perceived obstacles to youth entrepreneurial in Ghana. This will have a negative impact on youth entrepreneurship if care is not taken. It is recommended that, stakeholders precautiously design courses and policies to minimize the perception of entrepreneurship barriers and maximize motivational factors. Entrepreneurship education be designed to enhance skills and knowledge in entrepreneurship as an initiative to provide basics of such practical business practices and also to reorient students' career choices towards entrepreneurship. Awareness campaign of government support instruments should be done.

\section{References}

[1] Reynolds, P. D., Hay, M., \& Camp, S. M. (1999). Global Entrepreneurship Monitor: Executive Report. Kaufman Centre for Entrepreneurial Leadership, evelopment, 77, 311-327.

[2] Dei-Tumi, E. (2011), "National Youth Entrepreneurship Policy" Speech Delivered During a Workshop Organized by the Institute of Continuing and Distance Education, University of Ghana, on the Theme: "Policy Options for Youth empowerment in Ghana" at the Institute of African Studies on Friday, October 21, 2011.

[3] Shukla, S. and Awasthi, D. (2001), Study on Entry Barriers to Entrepreneurship, (Unpublished Report), New Delhi, Government of India, Ministry of Micro, Small and Medium Enterprises.

[4] United Nations Development Program (2000). World Development Report. United Nations.

[5] Mkhize, F., (2010). 'Shaping the Nation through Small Business: Focus on Budget 2010', Finweek, 25 February.

[6] Uneca and Ecowas (2010). Unemployment, Underemployment and Vulnerable Employment in West Africa: Critical Assessment and Strategic Orientations. http://www.uneca.org/wa/documents/RapportEco2010$\% 20$ Partie2ENG

[7] Kanyenze, G., Mhone, G. C. Z., and Sparreboom, T., (2000). "Strategies to combat youth unemployment and marginalization in Anglophone Africa". ILO/SAMAT Discussion. p. 14.

[8] Ghana Statistical Service. 2011. 2010 Population Census of Ghana. Ghana Statistical Service, Accra, Ghana.

[9] Gabreski, L. (2017). The future of Africa's economic development lies with young entrepreneurs. Retrieved from https://www.eventerprise.com/blog/future-africas-economicdevelopment-lies-young-entrepreneurs/

[10] Premand, P., Brodmann, S., Almeida, R., Grun, R., \& Barouni, M. (2016). Entrepreneurship education and entry into selfemployment among university graduates. World D1.

[11] Adenle, A. A. (2017). Building the African economy: Is president Obama's entrepreneurial public management program sustainable in Africa? Journal of Entrepreneurship and Public Policy, 6 (1), 92-107.
[12] Dzisi, S., Odoom, F. D., \& Gligah, B. (2018). Entrepreneurship training and skills development in Africa: Evidence from Koforidua Technical University, Ghana. International Journal of Economics and Business Research, 15 (4), 509-523.

[13] Luthje, C. \& Franke, N. (2003). The 'making' of an entrepreneur: Testing a Model of Entrepreneurial intent among engineering students at MIT. Research and Development Management, 33 (2), 135-147.

[14] Sitaridis, I. K. \& Kitsios, F. (2016). Students' Perceptions of

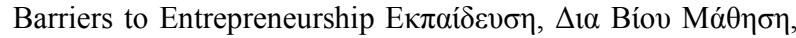

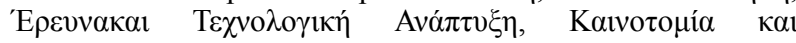
Оєкоvонía, 1: 524-535.

[15] Martins, S., Couchi, C., Parat, L., Carmine, F., Doneddu, R., Salmon, M. (2004) Barriers to entrepreneurship and business creation, European Entrepreneurship Cooperation Observatory.

[16] Kebaili, B., Al-Subyae, S. S., \& Al-Qahtani, F. (2017). Barriers of entrepreneurial intention among Qatari male students. Journal of Small Business and Enterprise Development, 24 (4), 833-849. https://doi.org/10.1108/JSBED-11-2016-0186

[17] Abimbola, O. H., Olowu, A. U., \& Paul, D. (2016). Youth Unemployment and Entrepreneurship Prospects in Nigeria: A Developmental Perspective. Ife Centre for Psychological Studies/Services, Ile Ife, Nigeria ISSN: 1117-1421

[18] Fox, L., Senbet, L. W., and Simbanegavi, W. (2016). Youth employment in Sub-Saharan Africa: Challenges, constraints and opportunities Journal of African Economies, 25 (2), i3-i15 http://dx.doi.org/10.1093/jae/ejv027

[19] Elder, S. et al., (2015). Labour market transitions of young men and women in Eastern Europe and Central Asia Geneva: ILO http://www.ilo.org/employment/areas/youthemployment/work-

foryouth/publications/regionalreports/WCMS_357353/lang-en/index.htm

[20] Elder, S. and Koné, K. S. (2014). Labour market transitions of young women and men in Sub-Saharan Africa. Geneva: ILO http://www.ilo.org/wcmsp5/groups/public/-ed_emp/documents/publication/wcms_235754.pdf

[21] Grant, U. (2012). Urbanization and the employment opportunities of youth in developing Countries Paper commissioned for the EFA Global Monitoring Report, Youth and skills: Putting education to work

http://www.youthmetro.org/uploads/4/7/6/5/47654969/217879e.pdf

[22] Betcherman, G. and Khan, T. (2015). Youth employment in Sub-Saharan Africa: Taking stock of the evidence and knowledge gaps Ottawa: IDRC https://www.idrc.ca/sites/default/files/sp/

[23] Baah-Boateng, W. (2014). Youth employment challenges in Africa: Policy options and agenda for Future research Paper presented at the AERC biannual conference in Lusaka, Zambia, December. https://www.researchgate.net/profile/William BaahBoateng2/ publication/272418275_Youth_employment_challenges_in_A frica Policy_options and agenda for_future

[24] Anyanwu, J. C. (2013). Characteristics and macroeconomic determinants of youth employment in Africa African

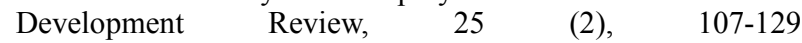
http://onlinelibrary.wiley.com/doi/10.1111/j.14678268.2013.12019.x/full 
[25] Msigwa, R. E., \& Kipesha, E. F. (2013). Determinants of Youth unemployment in Developing Countries: Evidences from Tanzania. Journal of economics and sustainable development, 4, 67-76.

[26] Wong, M Choo, S. (2009). Entrepreneurial intention: Triggers and barriers to new venture creation in Singapore. Singapore Management Review, 28 (2), 47-6.

[27] Benzing, C., \& Chu, M. H. (2009). A comparison of motivations of small business owners in Africa. Journal of Small Business and Enterprise Development, 16 (1), 60-77.

[28] Cooper, D. R. \& Schindler, P. S. (2003). Business Research Methods. New York: McGraw Hill Inc. Ghana Ministry of Youth and Sports. 2010. "National Youth Policy of Ghana: Towards an Empowerred Youth, Impacting Positively on National Development". Accra, Ghana.

[29] Pihie, Z. A. L. (2009). Entrepreneurship as a career choice: An analysis of entrepreneurial self-efficacy and intention of university students. European Journal of Social Sciences. 9 (2), 338-349.

[30] Leech, N. L., Barrett, K. C. \& Morgan, G. A. (2005). SPSS for intermediate statistics, use and interpretation. New Jersey: Lawrence Erlbaum Associates Inc.

[31] Zheng, Zeyu, Podobnik, Boris, Feng, Ling, \& Li, Baowen. (2012). Changes in cross-correlations as an indicator for systemic risk. Scientific reports, 2, 888.

[32] Billio, Monica, Getmansky, Mila, Lo, Andrew W, \& Pelizzon, Loriana. (2012). Econometric measures of connectedness and systemic risk in the finance and insurance sectors. Journal of financial economics, 104 (3), 535-559.

[33] Kritzman, Mark, Li, Yuanzhen, Page, Sebastien, \& Rigobon, Roberto. (2010). Principal components as a measure of systemic risk. 